

\title{
Holism versus Reductionism in Supply Chain Management: An Economic Analysis
}

\author{
Borja Ponte ${ }^{*}$, José Costas ${ }^{2}$, Julio Puche ${ }^{3}$, David de la Fuente ${ }^{1}$, and Raúl Pino ${ }^{1}$ \\ 1Department of Business Administration, University of Oviedo, Gijón, Spain \\ \{ponteborja*, david, pino\}@uniovi.es (* corresponding author) \\ ${ }^{2}$ Polytechnic Institute of Viana do Castelo, Valença, Portugal \\ josegual@esce.ipvc.pt \\ ${ }^{3}$ Department of Applied Economics, University of Burgos, Burgos, Spain \\ jcpuche@ubu.es
}

\begin{abstract}
${ }^{1}$ :
Since supply chains are increasingly built on complex interdependences, concerns to adopt new managerial approaches based on collaboration have surged. Nonetheless, implementing an efficient collaborative solution is a wide process where several obstacles must be faced. This work explores the key role of experimentation as a model-driven decision support system for managers in the convoluted decision-making process required to evolve from a reductionist approach (where the overall strategy is the sum of individual strategies) to a holistic approach (where global optimization is sought through collaboration). We simulate a four-echelon supply chain within a large noise scenario, while a fractional factorial Design of Experiments (DoE) with eleven factors was used to explore cause-effect relationships. By providing evidence in a wide range of conditions of the superiority of the holistic approach, supply chain participants can be certain to move away from their natural reductionist behavior. Thereupon, practitioners focus on implementing the solution. The Theory of Constraints (TOC) defines an appropriate framework, where the Drum-Buffer-Rope (DBR) method integrates supply chain processes and synchronizes decisions. In addition, this work provides evidence of the need for aligning incentives in order to eliminate the risk to deviate. Modeling and simulation, especially agentbased techniques, allows practitioners to develop awareness of complex organizational problems. Hence, these prototypes can be interpreted as forceful laboratories for decision making and business transformation.
\end{abstract}

\section{Keywords:}

Drum-Buffer-Rope; Model-Driven Decision Support Systems; OUT Policy; Theory of Constraints; Throughput Accounting.

\footnotetext{
${ }^{1}$ Abbreviations: ABM - Agent-based Modeling; DBR - Drum-Buffer-Rope; DoE - Design of Experiments; OUT Order-up-to; SCM - Supply Chain Management; TA - Throughput Accounting; TOC - Theory of Constraints.
} 


\section{Introduction}

Reductionism and holism represent two opposite philosophical approaches to problem solving. While the former is based on the "divide and conquer" paradigm (breaking down the problem into simpler and smaller parts), the latter underscores the idea that systems must be viewed as a whole and not as collection of parts. In this sense, when reductionism is applied to Supply Chain Management (SCM), the overall strategy is obtained as a sum of the individual strategies of the companies that conform the supply chain (i.e. local optimization). On the contrary, in a holistic context, these individual strategies are the result of an overall strategy defined by collaboration (i.e. global optimization). Therefore, supply chain members must tackle a dilemma [1]: deciding between favoring decisions which go in their own interest and accommodating those that consider the interest of the system as a whole.

Given that supply chains are growingly built on interrelationships, practitioners widely accept that holistic approaches play a crucial role in improving overall performance. Nevertheless, even though it might seem counterintuitive, reductionism is still widespread in real systems [2]. This approach results in a Nash equilibrium, which brings lower overall performance [3]. If each member ignores the impact of its actions on the other echelons, the maximization of individual metrics often occurs at the expense of the entire supply chain performance [4]. In this sense, local optimization has shown to be a major source of inefficiencies, such as the well-known Bullwhip Effect [5], that define a set of common issues faced by real supply chains -e.g. excessive inventories, low customer service level, and high production variability.

Under these circumstances, collaboration stands out as a key source of competitive advantages. This research work explores the key role of experimentation through 
Agent-Based Modeling (ABM) [6] as a powerful model-driven decision support system [7] for managers in the complex decision-making process of adopting a collaborative solution within the supply chain. These computer-based prototypes can be interpreted as forceful and risk-free laboratories for business transformation.

Firstly, this article aims to provide evidence of the fact that holistic approaches clearly outperform reductionist ones from an economic perspective. In addition, it uses experimentation techniques to define the sources where the upgrade is based on. It is only by understanding the improvement that supply chain actors can be certain when moving away from their natural reductionist behavior.

Once developed the awareness of practitioners through the economic comparison, they focus on adopting holistic solutions. The implementation of efficient solutions is a wide process that requires an integrative schema, where information sharing must be understood as an enabler. In this sense, experimentation aims to motivate the confidence between supply chain echelons. It is relevant to underline that the efficiency of the collaborative solution depends not only on the technical component but also on the acceptance level of the decision makers.

From that point on, adopting holistic approaches requires to integrate processes, synchronize decisions, and set up systemic performance indicators. This paper shows how to use the Theory of Constraints (TOC) [8] with that goal through modeling techniques, which has been compared to the inventory cost-optimal Order-Up-To (OUT) policy [9]. That is, TOC allows participants to define a systemic methodology to tackle the previously identified issues. This production paradigm manages the supply chain flows through the Drum-Buffer-Rope (DBR) method with a focus on the bottleneck and defines a systemic scorecard through the Throughput Accounting (TA). 
However, this is not enough. If there are huge differences in how the echelons benefit from collaboration, the holistic approach would not be viable. That is, collaboration must be aimed at achieving the optimal through a Nash equilibrium where the incentives to deviate are eliminated. For this reason, we last focus on the concept of "incentive alignment" [10]. The profit increase must reward the contribution of each node in order to avoid opportunistic behaviors. Agent-based prototypes can lead the supply chain to modify its costs structure with this aim.

By way of summary, Figure 1 describes the decision map of this research and shows how experimentation conducts, in each step, the adoption of a holistic management. This graph, assuming the reductionist approach is the baseline, underscores the need for five connecting features in order to implement efficient collaborative solutions [10].

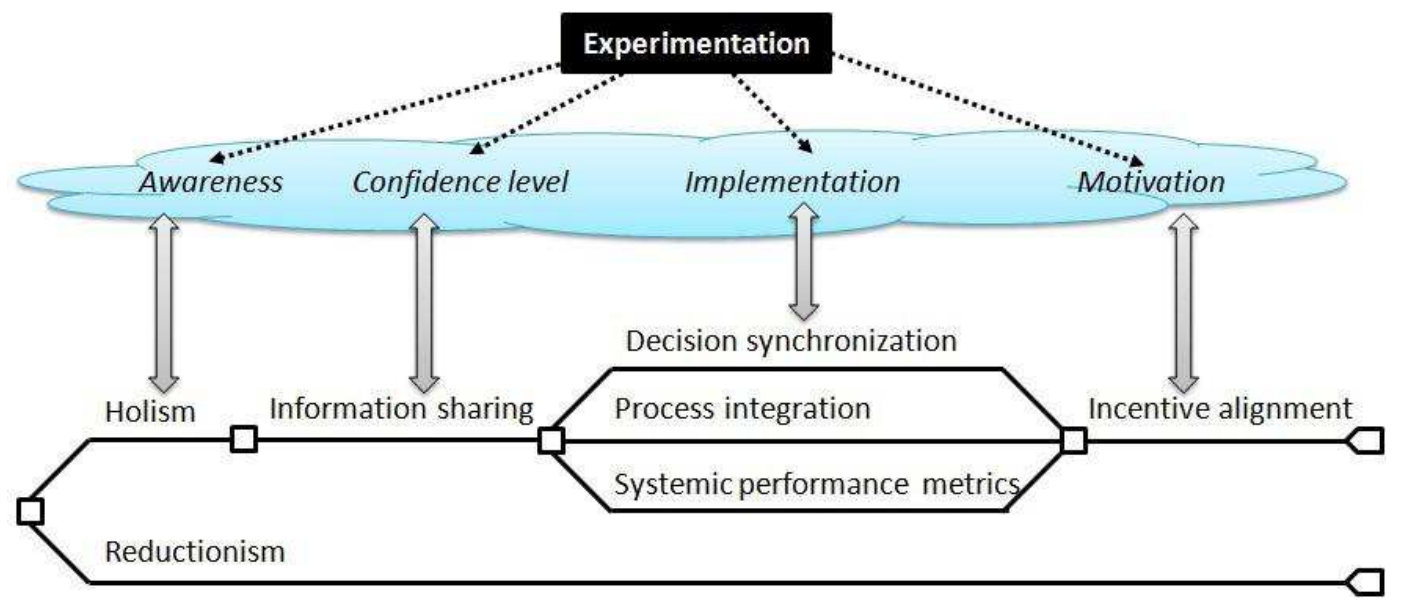

Fig. 1. Decision map of this research, which highlights the role of experimentation.

\section{Background: Literature Review}

Some key points of the research context are described below. We first present the main dilemma faced by supply chain members. Next, we introduce an integrative framework to take advantage of the collaborative approach. Lastly, the TOC is detailed as a systemic method to combat the issues derived from the reductionist approach. 


\subsection{The Dilemma of Supply Chain Practitioners.}

The main goal of companies is to make money now and in future [8]. To accomplish this objective, they can adopt two positions. This is the so-called dilemma [1]. This inherent decision for supply chain members can be expressed by Figure 2.

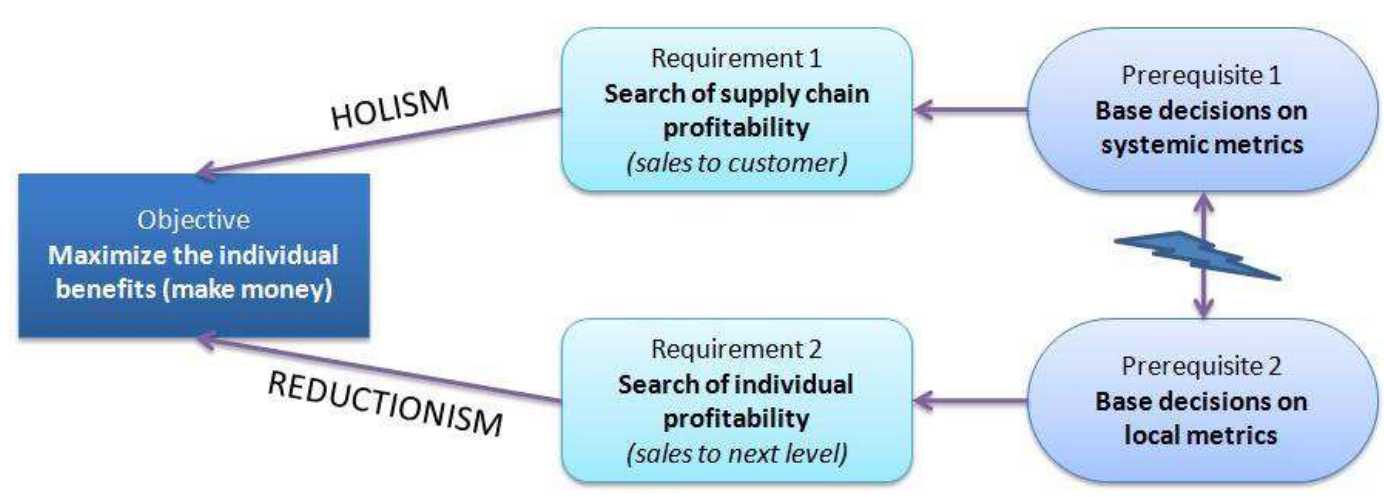

Fig. 2. The dilemma of supply chain members through an evaporating cloud (adapted from [1]).

The traditional approach to face this dilemma (to maximize individual performance) consists in seeking for protecting their individual profitability [4]. This reductionist behavior provokes win-lose games, in which each member looks for its own bargain at the expense of its partners [11]. Local optimization results in multiple forecasting, price fluctuations, and rationing games that (strengthened by order batching and lead times) translate into information distortion along the supply chain. This causes dramatic inefficiencies within the system, through the well-known Bullwhip Effect [12], e.g. low service levels and excessive fluctuations in inventories and orders.

From a holistic perspective, the various supply chain echelons understand that the best solution for the whole system leads to the best solution for them. Therefore, in order to maximize profit, they make decisions considering the global profitability, namely they use systemic performance metrics [1]. In a collaborative way, supply chain participants coordinate their processes and synchronize their decisions aimed at revenues from final customers instead of their own sales [4]. 


\subsection{An Integrative Framework for Supply Chain Collaboration.}

The literature on the subject mostly assumes holistic methods to outperform traditional management policies (based on reductionist principles) in terms of overall supply chain performance. However, practitioners find it difficult to address the issue of supply chain collaboration, which justifies why, even shown it superiority, it is not widespread in practice [13]. If a robust solution is not found, the menace of opportunistic behaviors arise, which creates an environment of uncertainty and complexity such that the cost of transacting under this context involves additional risk and expense [14]. Namely, the effectiveness of collaboration relies not only upon the integration of operations, but also upon the level to which efforts are aligned [13].

This fact highlights the relevance of defining an appropriate framework for supply chain collaboration where to obtain competitive advantages by working together [4]. This must be integrative, i.e. connecting different features of collaboration, such as the one proposed by Simatupang and Sridharan [10], which considers five edges:

(1) Information sharing, defined as the access to private data in all members' systems creating visibility at the different nodes on the overall system state.

(2) Decision synchronization, which refers to the extent to which the various echelons can orchestrate critical decisions at planning and execution levels.

(3) Incentive alignment, achieved through the process of sharing costs, risks, and benefits among the various participants in an equitable manner.

(4) Integrated processes, i.e. the design of the efficient supply chain flow that delivers products to end customers in a timely manner at lower costs.

(5) Systemic performance indicators, understood as the process of devising and implementing metrics that guide members to improve overall performance. 


\subsection{The Theory of Constraints (TOC) in Supply Chain Management (SCM).}

The TOC, presented by E. M. Goldratt [8], meant a major innovation in the production field. This management philosophy views any system as being limited in reaching a higher performance only by its bottleneck. Although it was first oriented on the manufacturing system, further development incorporates solutions for other business areas, such as SCM [15]. The TOC holistic paradigm has been shown to achieve breakthrough improvements in comparison with mass production alternatives in terms of lead time reduction, customer service level increase, and throughput growth [16].

For this reason, the TOC can be presented as the core of the collaborative solution, namely, it allows managers to integrate processes, synchronize decisions and set up a performance system [1]. Its logical thinking is expressed as a continuous improvement cycle with five steps [8]:

(1) To identify the bottleneck.

(2) To decide how to exploit the bottleneck.

(3) To subordinate everything else in the system to the previous step.

(4) To elevate the bottleneck.

(5) To evaluate if the bottleneck has been broken, and return to the beginning.

To manage the system, the TOC proposes the DBR methodology [8]. This pull-oriented strategy (i.e. replenishment is based on actual demand instead of on the forecast) aims to manage properly the bottleneck (ensuring its steady supply) through suitable coordination. It is named by its three main components. The drum, placed at the bottleneck, is a system pacemaker. The rest of the nodes follow its beat (production rate). The buffer protects the drum against variability, so that the full capacity in the bottleneck is exploited. The rope is the release mechanism that subordinates the entire 
system to the drum. The DBR configuration (planning state) is complemented with the buffer management (monitoring stage), which implies administrating the buffer along the different nodes in order to guide how the system is tuned for peak performance. Applying this method along the supply chain warrants the concentration of all members to what matters for the system as a whole [2].

In addition, the TOC defines a collaborative performance system to measure how the company performs. Unlike cost accounting (aimed at cost reduction), the TA [17] seeks to maximize the efficiency of the flow of value. Hence inventory is not considered as an asset, but a liability. The TA aims to enable managers to examine the link between process constraints and financial performance in decision making, i.e. to determine the real impact of their decisions. Three financial measures are proposed as complementary indicators: net profit (absolute terms), return on investment (relative terms), and cash flow (survival terms). The operational decisions are related to overall system success through the "cost bridge", defined by three metrics [17]:

(1) Throughput: the rate at which the system generates money through sales, i.e. the difference between the revenue and the total variable costs.

(2) Inventory: it includes not only raw material, work-in-progress, and finished goods stock but also all other invested money in the supply chain.

(3) Operating Expense: all the money the system spends in order to turn inventory into throughput, e.g. transformation and shipping costs.

\section{Problem Formulation: Supply Chain Model}

This section is devoted to detail the conceptual model of the agent-based supply chain that has been developed in this research, as well as the wide context where to confirm economic robustness of the results. 


\subsection{Supply Chain Scenario: Assumptions and Scope.}

In the same line as other relevant and recent studies [18], the supply chain has been analyzed under the Beer Game environment [19]. This is a traditional single-product supply chain with a serial structure formed by four echelons (factory, distributor, wholesaler, and retailer). With the aim of bringing it closer to reality, the noise sources have been expanded in order to consider common hurdles in real supply chains. It can be called the noise-extended Beer Game environment. The assumptions are as follows:

(1) Stochastic customer demand. Specifically, a normal distribution simulates demand. Both mean and standard deviation are selected by the experimenter.

(2) Stochastic lead time. Each node receives both product and orders within a time range (set by the user) after sent, defined by a continuous uniform distribution.

(3) Stochastic failure of products. In each product's action (including storage and transport) along the supply chain, there is a probability of failure, defined by the defective products rate, which is set by the experimenter.

(4) Constrained production (factory) and transportation (between the various echelons) capacity. The user defines these quantity limitations. However, unconstrained storage capacity has been considered.

(5) Non-negative condition of the order quantity. Each member cannot return the product to its supplier.

Figure 3 displays the parameter diagram that describes the scope of this study. In the centre, it shows the overall system function responsible for transforming raw materials into finished products. Among the nodes, the material flow (from the factory to the retailer) refers to the shipping of the product, while the information flow (in the opposite direction) represents the orders. At the top part, the noise sources 
(uncontrollable factors) that threaten the supply chain can be seen divided into internal (lead times, defective products, and storage) and external (demand variability, transport, and raw materials). At the bottom part, the parametric space (controllable factors) highlights the factors to be modified. The extensive costs scenario and the performance (both financial and operational) metrics explained below are also shown.

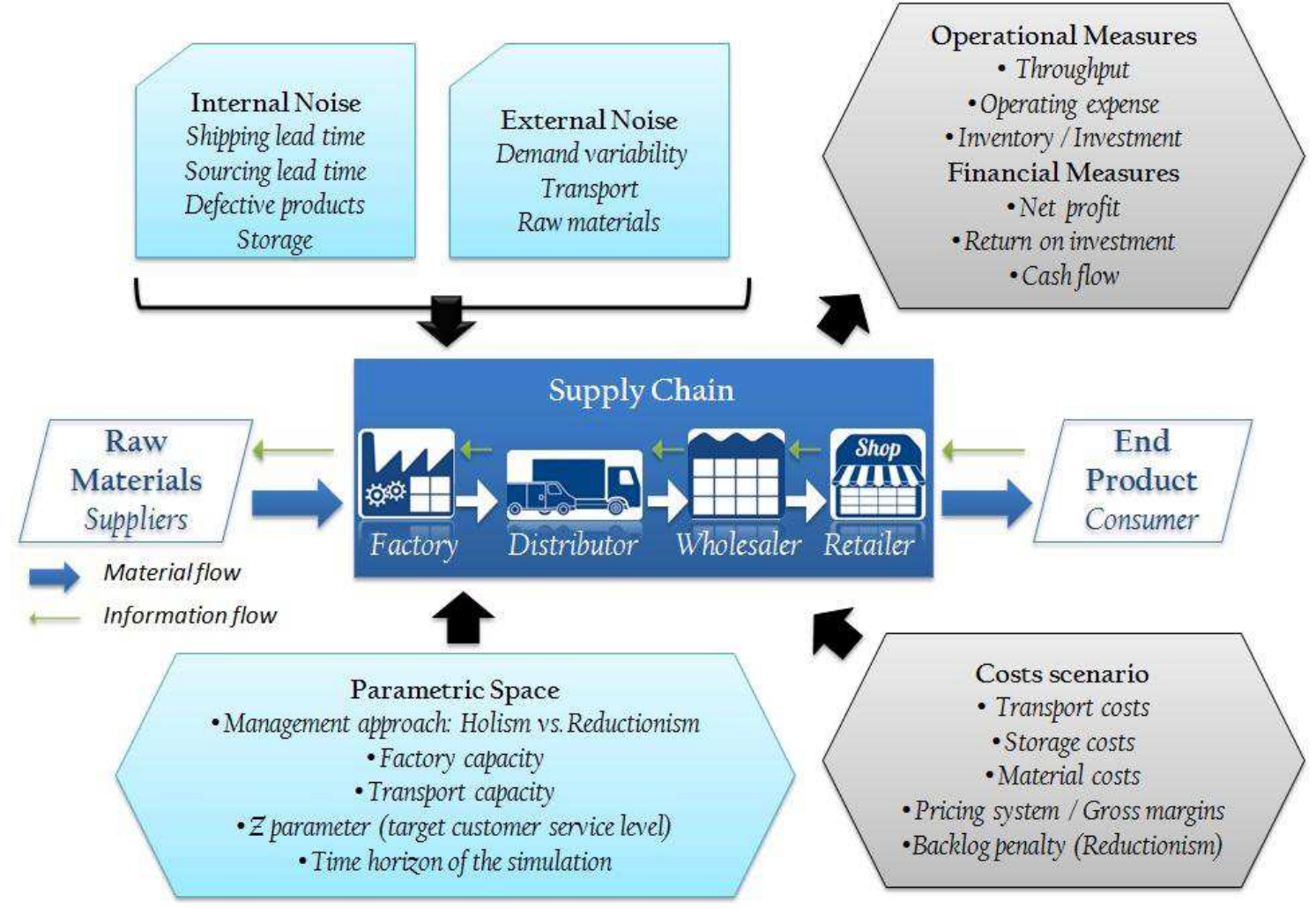

Fig. 3. Scope of the research, by means of a parameter diagram.

\subsection{Economic Model and Performance Metrics.}

The economic model seeks to imitate the main revenues and costs faced by real supply chain members. Income in the overall system is only generated through selling the product (to customer). In each node, money is made by sales to the next echelon. Expenditure is incurred in three ways: storage, transport, and provisioning. All of them have been considered to be proportional. Obviously, the provisioning cost of each echelon means the income for the previous one. Hence, a pricing system must be defined in the supply chain. All these economic parameters are set by the user. 
As explained, the TA is supported on three operational measures. According to TOC principles, the throughput is the difference between the revenue through sales (selling price times sales quantity) and the variable costs related to purchases (buying price times purchase quantity). Note that the gap between sales and purchase quantities is due to defective products and storage. The operating expense is calculated by adding storage and transport costs, as both are assumed to transform inventory into throughput. In the reductionist approach, this expense is adjusted by the difference between the money paid and received due to backorder penalty (as it is a usual practice in reductionist systems). Finally, the inventory in terms of TA is obtained by estimating the economic value of the products that are stored in each node.

From that point on, the key financial indicators can be easily obtained [17]. The net profit is expressed as the difference between throughput and operating expense, the cash flow considers, besides the above difference, the change of investment in the same horizon, and the return on investment is the net profit divided by the inventory. These metrics can be obtained for the overall supply chain (in the holistic supply chain) or node by node (in the reductionist system).

Figure 4 outlines the economic model of the supply chain, including the three operating metrics and the main financial measure (net profit).

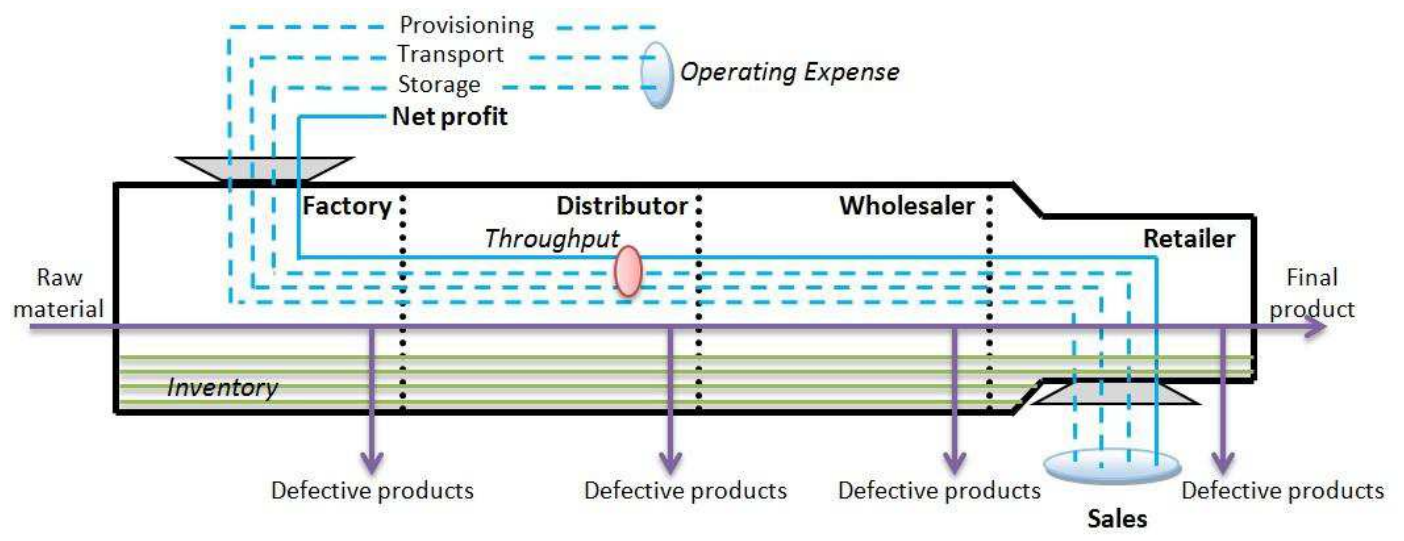

Fig. 4. Overview of the economic model of the supply chain, with the operating metrics. 


\subsection{Reductionist Approach: The Order-Up-To (OUT) Inventory Policy.}

In the non-collaborative management, each supply chain echelon communicates only with the previous one (to receive an order and to send the product) and with the next one (to place an order and to receive the product). Therefore, customer demand is only known by the retailer. In this mode, orders not fulfilled in time are backlogged, as usual in these replenishment models [9]. In each node, these backorders (involving an economic penalty) are fulfilled as soon as on-hand inventory becomes available.

This approach has been implemented through the OUT method. These policies are often used in the real world, given the usual practice in retailing to replenish very frequently [5] and because it is optimal in terms of inventory and shortage costs [20].

The classic OUT method is a periodic review system for issuing orders depending on demand forecasting and (both on-hand and on-order) inventory position, in order to bring the inventory position up to a defined level. That is, the order rate is the sum of the forecast, the gap between actual and target net stock (on-hand inventory), and the discrepancy between actual and target work-in-progress (on-order inventory). In this research, the demand has been forecast using a three-period moving average.

Both the target work-in-progress and the target net stock (a safety stock) are considered to be variables. Its sum to the forecast defines the OUT point. The former aims to cover the lead time between nodes, so it is easily estimated as the forecast times the average shipping lead time. The latter is aimed to protect supply chain nodes from demand variability and from internal noise sources (variability in lead times and defective in products). It is proportional to the demand standard deviation, to the lead time range, and to the estimated defective products. Each term in multiplied by the parameter $\mathrm{Z}$, set by the user and related to the desired service level. 
In the reductionist system, the discrete operation (sequence of events) of each node is summarized by Figure 5 for the distributor. At the beginning of each period, the product is received from the factory and it is stocked up. Then, the order is received from the wholesaler, and the net stock is checked in order to prepare the shipping. If the order can be fulfilled (besides considering previous backlog), the required quantity is sent; otherwise, backlog is generated and the available product is shipped. The next steps depend on the previously explained OUT policy. Notice both flows are delayed due to the lead time. The operation is similar for the other nodes.

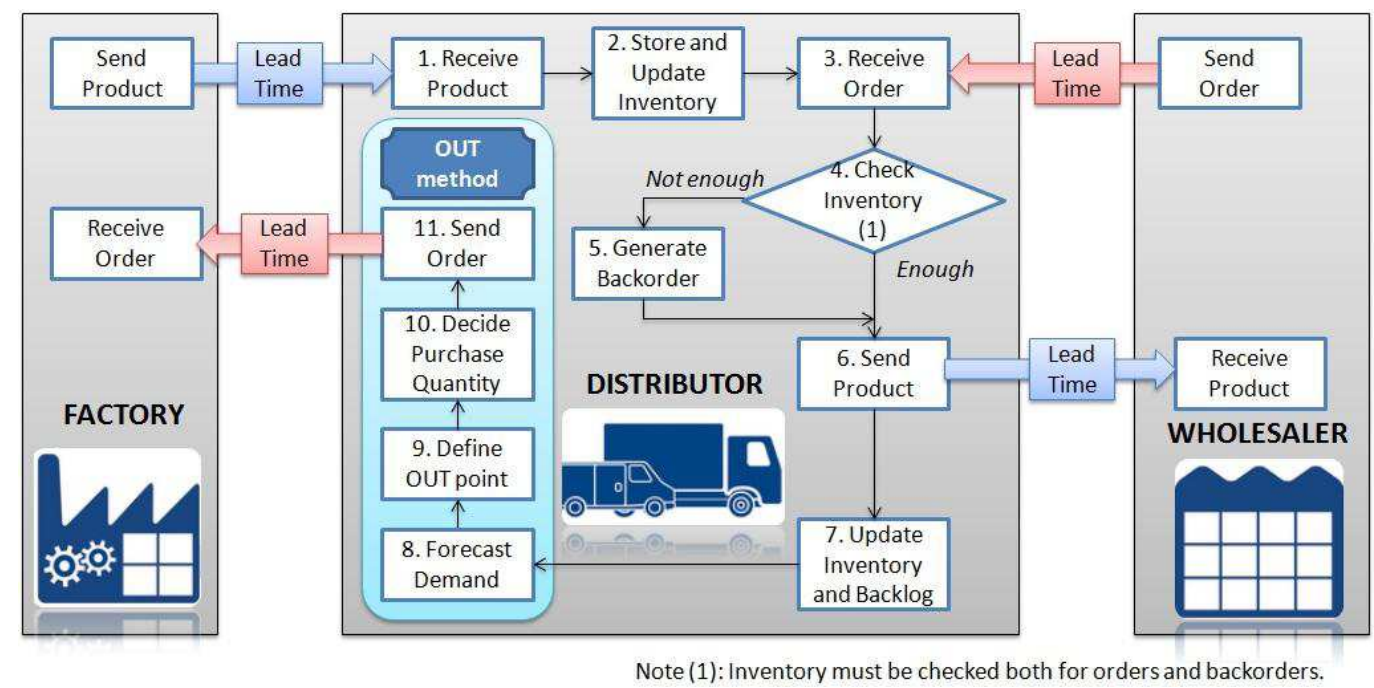

Fig. 5. Sequence of events for the distributor when applying the OUT policy.

\subsection{Holistic Approach: The Drum-Buffer-Rope (DBR) Methodology.}

Under the collaborative approach, the system is ruled by a kind of headquarters that accounts for the interest of the whole supply chain, taking decisions on the basis of greater visibility (supported by information sharing). Accordingly, the various nodes behave as required to protect the overall supply chain function.

From that point on, the holistic approach has been implemented through TOC principles, which are based on prioritizing the system bottleneck. In particular, the DBR method leads to both synchronize the entire sequence of integrated activities 
required to deliver products and to create effective processes aimed at achieving breakthrough improvements in system performance and reliability [21].

According to TOC logical thinking, the first step is to identify the bottleneck. In supply chains, the bottleneck tends to be the sales constraint as (production, transport, and storage) capacities are usually higher than demand [22]. Under this scenario, the demand is an external constraint beyond the supply chain sphere of influence. Hence, the bottleneck cannot be elevated or broken, and consequently the fourth and fifth steps of the improvement cycle are not required.

That is, the key points are the second and third steps, which define the sequence of events through the DBR method. On the one hand, the supply chain must efficiently exploit the bottleneck. This means to sell the product at the retailer, i.e. to minimize lost sales. To this end, the drum is placed at the retailer. This must beat out (define) the production and distribution rate for the whole system according to the actual demand. On the other hand, the other nodes must be subordinated to the bottleneck. In this sense, the retailer is protected from shortages, and thus the supply chain as a whole, against variation.

To subordinate the factory, the distributor, and the wholesaler to the bottleneck, we need the buffer and the rope [23]. The buffer is aimed at protecting the bottleneck through time. Uncertainty in the supply chain (demand, lead times, and defective products) must not increase lost sales. Thus, the buffer refers to the time period between releasing the material and the drum due date. For each node, the buffer considers the maximum lead time between itself and the customer. The rope is the release timing. It can be understood as a real-time feedback between the drum and the node operation. It should be noted that the rope length covers the same as the buffer 
duration. Tying the rope ensures that excess flow cannot be admitted. In this sense, the rope defines how much to order: the difference between the desired (considering the drum rate along the buffer time, and a safety stock to protect against demand variability and defective products) and the actual (sum of the net stock and shipping product) supply chain inventory. As the overall inventory is constrained, the Bullwhip Effect is dramatically reduced.

This DBR configuration, where the systemic condition to tie the different members through time (not by product) is established, is the planning stage. It is aimed to operate the system. Subsequently, a second stage is required each time period [2]. In the control stage (aimed at keeping a running check of the system efficiency), the buffer is managed along the intermediate members. Buffer management consists in moving the flow so that arrival happens on time at the bottleneck.

The main ideas explained above are displayed in Figure $6 b$ (it highlights the role of the three main components of the DBR method) in contrast to Figure $6 a$, which shows the basic ideas of the OUT policy. It should be noted that the factory decides the production orders that are placed based on the recent demand, while the rest of the nodes compensate the flow dissipated downstream after shipping. They calculate the rope length to the drum position, and make the order decision based on its downstream buffer to the bottleneck. This way, each supply chain member decides the quantity to dose subordinated to the bottleneck, so these dissipative orders do not have lead time nor generate backorders since the next dosage again obey the bottleneck [24]. On the contrary, note that in the reductionist system the nodes consider the upcoming demand and local inventories to order. Youngman [22] has developed an outstanding guide for TOC implementation in production and distribution systems, which can be consulted to get further detail. 


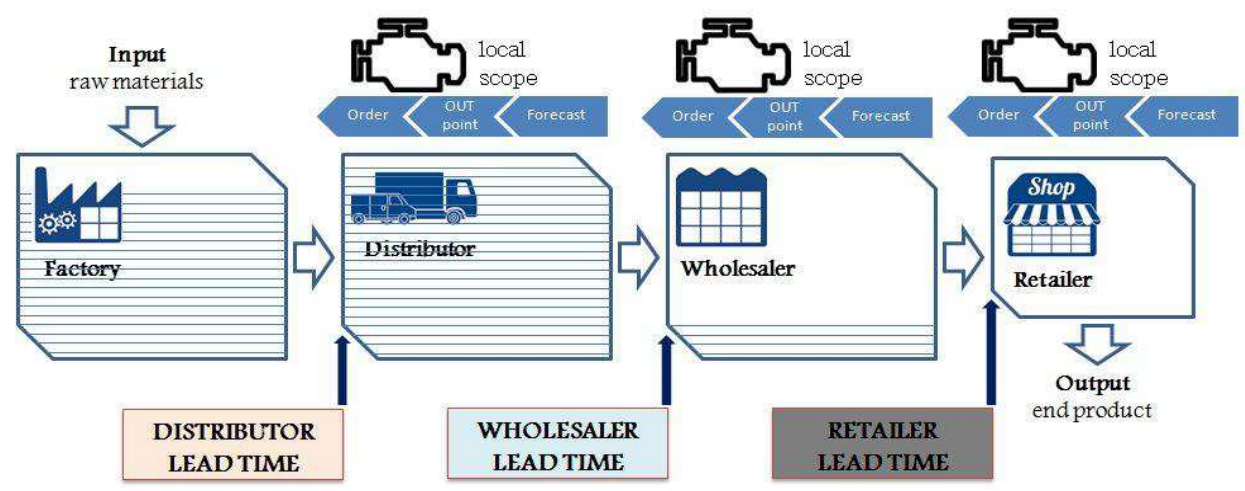

Fig. 6a. Overview of the supply chain, when working according to the OUT policy.

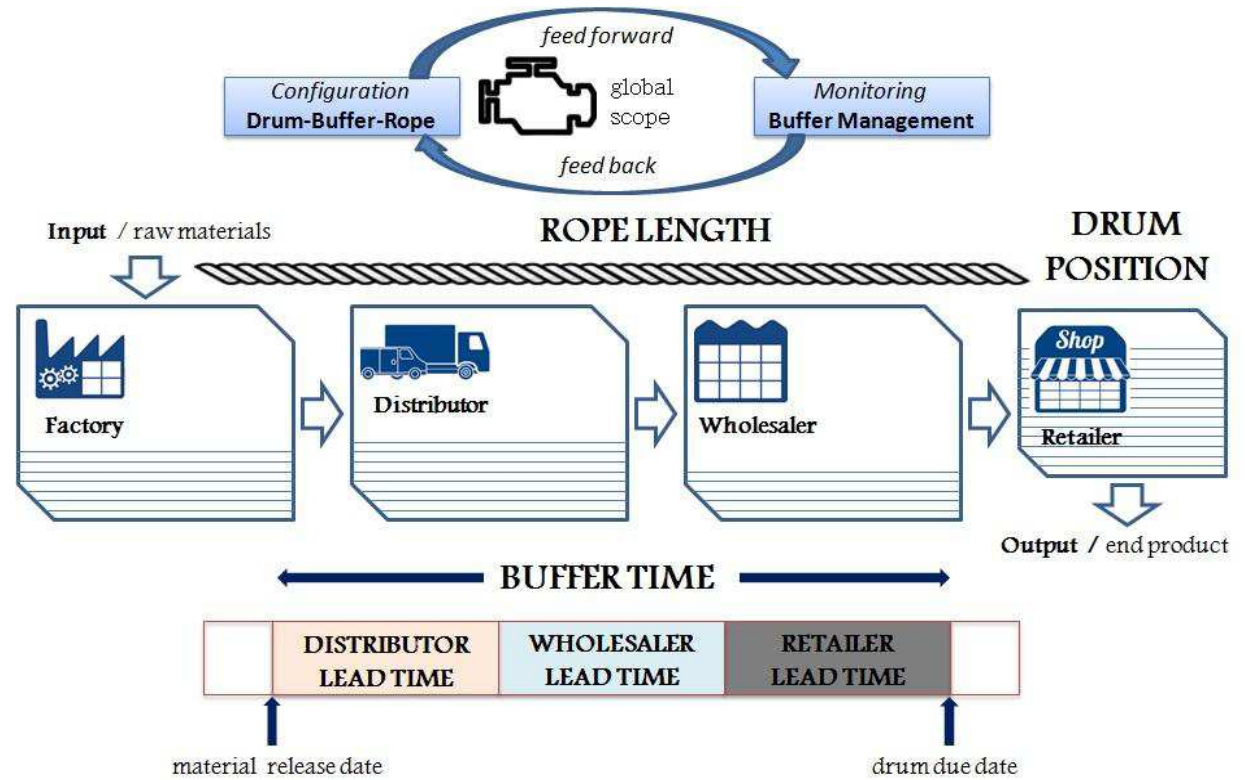

Fig. 6b. Overview of the supply chain, when working according to the DBR methodology.

\section{Agent-Based Development of the System}

In order to carry out the experimental approach aimed at comparing a supply chain managed using the OUT policy versus the same system ruled by TOC principles, the noise-extended Beer Game environment was required to be modeled. From the different available alternatives to create this model, we chose ABM [6].

$\mathrm{ABM}$ is a decentralized approach to model design emerging analytical method for social sciences, aimed at simulating the actions and interactions of autonomous agents (between them and with the environment) with a view to assessing their effects on the system as a whole [6]. This modeling approach follows the underlying notion that 
complex systems are built bottom-up. ABM fits in computational science [25] and is a very suitable approach when the problem is intractable by analytical tools, when the theoretical approach might be not reliable, or the experimentation with a real system is unfeasible or costly; all of which apply in our case. Actually, ABM is largely used to analyze the complex behavior of supply chains [26].

As ABM has its roots in Complex Adaptive Systems [27], we have extensively used these mechanisms to build our model: the agents are tagged (can be distinguished), they have internal and polymorphous rules to represent decision making, and the model is created by using building-blocks (aggregating simpler reusable components). The system has been implemented using NetLogo 5.1.0 [28]. NetLogo is a multi-agent programmable modeling environment continuously developed by the Center for Connected Learning and Computer-Based Model (Northwestern University).

We have used different breeds (types) of agents to represent the system, such as actors (supply chain echelons), events (that trigger the action), entities (representing material and orders), records (performance metrics), and police (for controlling and debugging). Each one has its own attributes and methods. Thus, agents are heterogeneous [29].

The engineering of the agent-based model consists in making the agents to follow discrete-event cues and make them behave as finite-state machines. For this reason, a Future Event List (FEL) artifact is a core feature in the model, as it cares about cueing future events to deploy action. In addition, the model is based on a finite-state engine, which makes actors roam through a cyclic map of states to perform the previously defined sequence of events (see Figures 5 and 6). At the beginning of each cycle (local for each agent), the agent is idle. At the end, it reports the main results. Therefore, agents are autonomous [30] in terms of their decision making. 
Two essential phases in modeling are verification (checking cohesion and consistency) and validation (predictions must match the reality). In this regard, the model was developed following strict rules of clean code, test-driven development, and robust engineering. We used anti-error mechanisms (e.g. cross checking) for early detection of system malfunctions. In addition, several acceptance tests have been used to confirm that the model exhibits a known behavior when exposed to controlled conditions.

\section{Simulation Study and Discussion of Results}

This section presents the Design of Experiments (DoE), shows the results obtained in this research work, and discusses them based on the stated objectives.

\subsection{Design of Experiments (DoE).}

This DoE aims to assess the impact of moving from the OUT policy to a DBR-managed supply chain in a wide variety of scenarios, both from an overall and a node-by-node perspective. Using Goldratt's principles, results $(Y)$ are expressed in terms of net profit $(N P)$ in the entire supply chain $(i=0)$ and in the four members $(i=1, \ldots, 4)$. This largerthe-better indicator represents the critical concern the various supply chain members.

The experimentation approach shown in Eq. (1) is defined as a function of eleven variables. In other words, treatments have been performed on different scenarios defined by the combination of eleven factors; see the parameter diagram in Figure 3. Four of them are controllable: management policy (X1), production capacity (X2), transport capacity (X3), and Z safety parameter (X4). The remaining seven factors are noise: standard deviation of the demand (Z5), transport cost (Z6), storage cost $(Z 7)$, defective product rate $(Z 8)$, gross margin of the supply chain echelons $(Z 9)$, range of the order lead time (Z10), and range of the product lead time (Z11). All of them are real 
factors except X1 that is a categorical variable. It should also be considered the unexplained part of the system response, i.e. the residuals $(\xi)$. Therefore, it is a fractional factorial DoE with eleven factors.

$$
Y=\left[N P_{i}\right]_{i=0}^{i=4}=f(X 1, X 2, X 3, X 4, Z 5, Z 6, Z 7, Z 8, Z 9, Z 10, Z 11)+\xi
$$

Each factor in the DoE has two levels. Table 1 outlines the levels that have been defined.

We have sought for wide enough ranges in these variables where to derive conclusions with general implications for real supply chains. Note that we have selected as fixed those factors that act like an anchor for the others, see Table 1.

Table 1. DoE: Definition of the factors and levels.

\begin{tabular}{|c|c|c|c|}
\hline Factor & Role & Level 1 (Low*) & Level 2 (High*) \\
\hline Management policy (X1) & Controllable & Holism - DBR & Reduct. - OUT \\
\hline Production capacity (X2) & Controllable & $140 \mathrm{u}$ & $9876 \mathrm{u}$ \\
\hline Transport capacity (X3) & Controllable & $140 \mathrm{u}$ & $9876 u$ \\
\hline$Z$ safety parameter $(X 4)$ & Controllable & $1.282(90 \%)$ & $2.326(99 \%)$ \\
\hline St. Dev. of the demand (Z5) & External Noise & $10 \mathrm{u}$ & $30 \mathrm{u}$ \\
\hline Transport cost (Z6) & External Noise & $0.002 \$ / \mathrm{u} /$ period & $0.01 \$ / \mathrm{u} /$ period \\
\hline Storage cost (Z7) & Internal Noise & $0.002 \$ / \mathrm{u} /$ period & $0.01 \$ / \mathrm{u} /$ period \\
\hline Defective products rate $(\mathrm{Z} 8)$ & Internal Noise & $500 \mathrm{ppm}$ & $6000 \mathrm{ppm}$ \\
\hline Gross margin (Z9) & Internal Noise & $0.20 \$ / u$ & $0.60 \$ / \mathrm{u}$ \\
\hline Order lead time: Range (Z10) & Internal Noise & 0 periods & 1 period \\
\hline Product lead time: Range (Z11) & Internal Noise & 1 period & 4 period \\
\hline Mean of the demand (Fixed) & External Noise & $100 \mathrm{u}$ & \\
\hline Material cost (Fixed) & External Noise & $0.40 \$ / \mathrm{u}$ & \\
\hline Order lead time: Min (Fixed) & Internal Noise & 1 period & \\
\hline Product lead time: Min (Fixed) & Internal Noise & 4 periods ${ }^{* *}$ & \\
\hline Backorder penalty (Fixed) & Internal Noise & $0.04 \$ / \mathrm{u} /$ period & \\
\hline \multicolumn{4}{|c|}{ 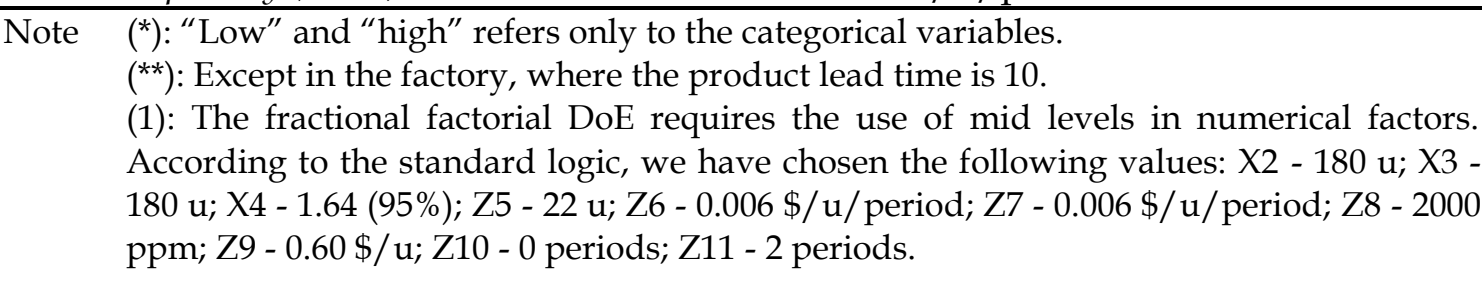 } \\
\hline
\end{tabular}

We have employed 10 and 30 as values for the standard deviation of the demand, since the coefficient of variation (i.e. the ratio of the standard deviation to the mean of the demand, which is 100) of retail series is usually lower than $50 \%$ [5]. Regarding the 
capacities, the lower level introduces a significant constraint in the system (40\% greater than the average demand, which reduces the supply chain ability to react when backlog occurs especially when suffering from the Bullwhip Effect), while the higher level creates an unconstrained environment. In terms of the safety stock, the use of $90 \%$ (it is considered that lower values provokes a high number of lost sales) and $99 \%$ (it is considered that greater values result in excessive storage costs) to define the interval of target customer service levels is common both in research studies and in practice [31].

Although the range of the order lead time is usually considered as null (i.e. fixed lead time, level 1 in our DoE), we have also chosen a range of 1 (level 2) to analyze the impact of this variable. At the same time and since the minimum value is 4 , the range of the product (shipping) lead time varies between 1 (low variability; lead time between 4 and 5) and 4 (high variability; lead time between 4 and 8). These ranges can be understood as common in practice; e.g. see [32]. In terms of the defective product rate per time unit, we have selected an interval from 500 to 6,000 parts per million, since the model have been designed to usually operate within the industry-average area in the six-sigma scale [33]. From this point on, the model may explore other points either in the best-in-class area or in the non-competitive area of the six-sigma scale.

Regarding the economic factors, the unit material cost $(\$ 0.40)$ sets the economic scale. The unit gross margin per node has been decided to cover an interval from the $50 \%$ to the $150 \%$ of the material cost, while the ratio of the transport and storage costs per period have been chosen to be between $0.5 \%$ and $2.5 \%$. Nonetheless, the economic values are meaningless in their selves, but the relevant point is their financial implications on the supply chain. For example, the Return on Sales (ratio of the operating profit to the sales revenue) in the tests performed varies from $-4 \%$ to $70 \%$, which can be assume to largely cover the usual financial situation of real systems. 
Table 2. DoE: Inner array (orthogonal matrix) and results of the different treatments.

\begin{tabular}{|c|c|c|c|c|c|c|c|c|c|c|c|c|c|c|c|c|}
\hline Run & X1 & $\mathrm{X} 2$ & X3 & $\mathrm{X} 4$ & $\mathrm{Z5}$ & Z6 & $\mathrm{Z7}$ & $\mathbf{Z 8}$ & Z9 & Z10 & Z11 & NP SC & NP Fact & NP Dist & NP Whol & NP Ret \\
\hline 1 & OUT & Low & Mid & Low & Low & High & High & Low & High & Low & Low & $\$ 27,044.56$ & $\$ 5,718.33$ & $\$ 4,945.86$ & $\$ 7,264.44$ & $\$ 9,115.93$ \\
\hline 2 & $\mathrm{DBR}$ & High & High & Low & Low & High & Low & High & High & Low & Low & $\$ 43,686.43$ & $\$ 16,154.12$ & $\$ 8,339.36$ & $\$ 10,318.59$ & $\$ 8,874.36$ \\
\hline 3 & $\mathrm{DBR}$ & Low & High & High & Low & High & High & Low & Low & High & High & $\$ 8,205.18$ & $\$ 3,536.14$ & $\$ 947.53$ & $\$ 2,390.29$ & $\$ 1,331.22$ \\
\hline 4 & DBR & High & Low & Low & Low & Low & High & Low & Low & Low & High & $\$ 11,757.21$ & $\$ 3,002.22$ & $\$ 2,859.05$ & $\$ 2,887.18$ & $\$ 3,008.76$ \\
\hline 5 & OUT & High & Low & High & Low & Low & Low & High & High & High & High & $\$ 34,762.44$ & $\$ 8,875.50$ & $\$ 7,079.23$ & $\$ 9,812.19$ & $\$ 8,995.52$ \\
\hline 6 & OUT & Low & Low & High & Low & High & Low & High & Mid & Low & Low & $\$ 16,271.97$ & $\$ 4,440.30$ & $\$ 1,683.10$ & $\$ 4,602.04$ & 46.53 \\
\hline 7 & DBR & Low & High & High & High & Low & High & Low & High & High & Low & $\$ 49,044.95$ & $\$ 13,823.97$ & $\$ 11,912.50$ & $\$ 11,968.64$ & $\$ 11,339.84$ \\
\hline 8 & DBR & Low & Low & Low & Mid & Low & High & High & High & High & Low & $\$ 46,234.37$ & $\$ 15,300.15$ & $\$ 11,221.03$ & $\$ 10,699.88$ & $\$ 9,013.31$ \\
\hline 9 & OUT & High & High & High & High & High & High & High & High & Low & High & $\$ 18,000.34$ & $\$ 287.99$ & $\$ 2,652.27$ & $\$ 7,475.88$ & $\$ 7,584.20$ \\
\hline 10 & DBR & Low & Low & High & High & High & Mid & High & Low & Low & High & $\$ 2,299.29$ & $\$ 4,418.99$ & $\$-1,799.86$ & $\$ 1,037.15$ & $\$-1,356.99$ \\
\hline 11 & OUT & Low & Low & Low & High & High & Low & Low & Low & High & Low & $\$ 8,971.63$ & $\$ 1,816.87$ & $\$ 101.50$ & $\$ 3,565.77$ & $\$ 3,487.49$ \\
\hline 12 & OUT & High & High & Low & High & High & High & High & Low & High & Low & $\$-2,972.76$ & $\$-4,309.84$ & $\$-2,871.24$ & 21.81 & $\$ 2,286.51$ \\
\hline 13 & DBR & Low & High & Low & High & Low & Low & High & Low & Low & Low & $\$ 11,144.96$ & $\$ 5,062.66$ & $\$ 1,577.08$ & $\$ 2,260.19$ & $\$ 2,245.03$ \\
\hline 14 & OUT & High & Low & High & High & Low & High & Low & Low & Low & Low & $\$ 3,896.98$ & $\$-4,974.51$ & $\$ 1,606.11$ & $\$ 3,587.80$ & $\$ 3,677.58$ \\
\hline 15 & OUT & Low & High & Low & High & Low & Low & Low & High & Low & High & $\$ 33,491.43$ & $\$ 7,596.18$ & $\$ 6,918.58$ & $\$ 9,335.48$ & $\$ 9,641.19$ \\
\hline 16 & DBR & High & Low & Low & High & High & Low & Low & High & High & High & $\$ 45,336.74$ & $\$ 14,061.00$ & $\$ 9,395.73$ & $\$ 11,464.13$ & $\$ 10,415.88$ \\
\hline 17 & OUT & Low & High & Low & Low & Low & High & High & Low & High & High & $\$ 5,176.96$ & $\$-331.77$ & $\$-23.12$ & $\$ 2,230.43$ & $\$ 3,301.42$ \\
\hline 18 & DBR & High & High & High & Low & Low & Low & Low & Low & High & Low & $\$ 15,503.55$ & $\$ 4,411.51$ & $\$ 3,628.99$ & $\$ 3,857.10$ & $\$ 3,605.95$ \\
\hline 19 & OUT & Mid & Mid & Mid & Mid & Mid & Mid & Mid & Mid & Mid & Mid & $\$ 16,697.15$ & $\$ 2,800.37$ & $\$ 2,890.40$ & $\$ 5,280.46$ & $\$ 5,725.92$ \\
\hline 20 & DBR & Mid & Mid & Mid & Mid & Mid & Mid & Mid & $\mathrm{Mid}$ & Mid & Mid & $\$ 28,205.50$ & $\$ 8,521.28$ & $\$ 6,279.26$ & $\$ 7,047.98$ & $\$ 6,357.07$ \\
\hline 21 & OUT & Mid & Mid & Mid & Mid & Mid & $\mathrm{Mid}$ & Mid & Mid & Mid & Mid & $\$ 16,547.36$ & $\$ 2,215.26$ & $\$ 3,078.03$ & $\$ 5,515.68$ & $\$ 5,738.39$ \\
\hline 22 & DBR & Mid & Mid & Mid & Mid & Mid & Mid & Mid & Mid & Mid & Mid & $\$ 27,655.38$ & $\$ 8,431.51$ & $\$ 5,798.61$ & $\$ 7,047.75$ & $\$ 6,377.51$ \\
\hline 23 & OUT & Mid & Mid & Mid & Mid & Mid & Mid & Mid & Mid & Mid & Mid & $\$ 16,094.82$ & $\$ 1,977.17$ & $\$ 3,007.92$ & $\$ 5,249.42$ & $\$ 5,860.31$ \\
\hline 24 & $\mathrm{DBR}$ & Mid & Mid & Mid & Mid & Mid & Mid & Mid & Mid & Mid & Mid & $\$ 27,032.78$ & $\$ 8,601.08$ & $\$ 5,571.46$ & $\$ 6,613.59$ & $\$ 6,246.65$ \\
\hline
\end{tabular}

Notes (1): This table highlights the collaborative treatments.

(2): "NP SC" represents the overall net profit of the supply chain, while the last four columns show the net profit of the four supply chain members.

(3): A more detailed version of the results is available upon request. 


\subsection{Layout and results.}

Following Fisher's strategy [34], an 18-row orthogonal inner array (block 1) has been created. Each row represents a treatment defined by a different combination of factors. This technique allows one to draw conclusions from a broad design space exploring some strategic points. In addition, 6 additional runs have been carried out (block 2). These are the same intermediate treatment replicated three times for both management approaches, with the aim of checking consistency of results and system stability. The former was verified through a 2-variance Levene test, which showed that differences are not significant. Regarding the latter, we verified there is not lack-of-fit problem. A time horizon of 250 periods was used for each treatment. Table 2 displays the results.

\subsection{Overall Analysis of the Results.}

First, we focus on the results of the entire supply chain. Broadly speaking, this experimentation provides evidence about the sound impact of DBR application to improve supply chain profitability in comparison with the OUT inventory policy. While the average net profit is $\$ 26,342.20$ when DBR manages the supply chain, it is $\$ 16,165.24$ when the OUT inventory policy is applied in each participant. This means an improvement of $63 \%$. Nonetheless these impressions must be verified statistically. Due to this reason, Yates' algorithm was applied to compute the estimates of main effects in this factorial experiment. JMP [35] statistical software has been used.

Figure 7 shows that a linear model is enough to explain the results obtained. As the coefficient of determination $\left(\mathrm{R}^{2}\right)$ is considerably high, the variability is more absorbed through the model than by the residual. Hence, there is a large capacity to explain system response between controllable and noise factors. The ANOVA study concludes that the model is relevant ( $p$-value significantly lower than 5\%). 


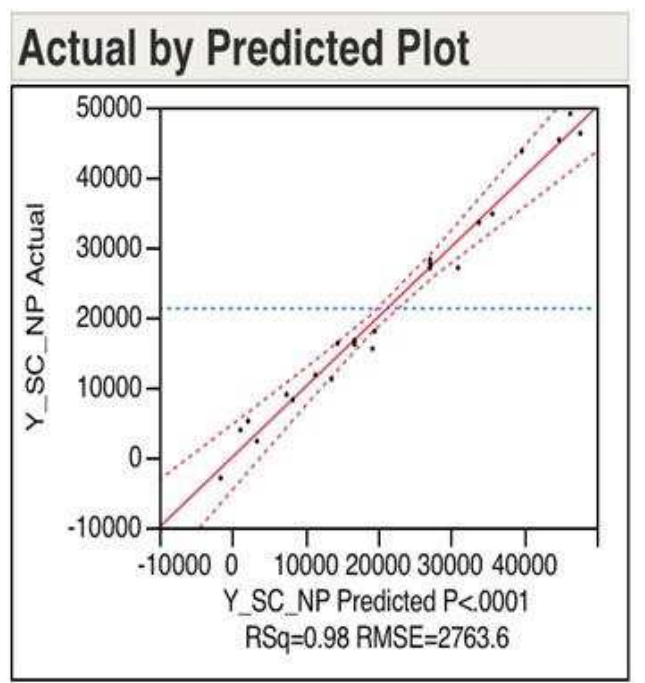

\begin{tabular}{lr}
\hline Summary of Fit & \\
\hline RSquare & 0.982118 \\
RSquare Adj & 0.965727 \\
Root Mean Square Error & 2763.646 \\
Mean of Response & 21253.72 \\
Observations (or Sum Wgts) & 24
\end{tabular}

Analysis of Variance

\begin{tabular}{lrrrr}
\multicolumn{4}{c}{ Sum of } & \\
Source & DF & Squares & Mean Square & F Ratio \\
Model & 115033827168 & 457620652 & 59.9157 \\
Error & 1291652842.8 & 7637736.9 & Prob $>$ F \\
C. Total & 235125480010 & & $<.0001^{*}$
\end{tabular}

Fig. 7. Summary of the Yates' results that confirm the validity of the linear model obtained.

Table 3 displays the effect diagram, with the parameter estimates (and the standard error), the t-ratio (which tells about the relative importance of each factor), and the $\mathrm{p}$ value. This shows six significant factors at the confidence level 95\%. As expected, the management policy is one of them. This one and the gross margin are the more relevant factors. That is, the main hypothesis is confirmed: the holistic DBR method significantly outperforms the reductionist OUT. On the other hand, although both are relevant, transport cost has shown to be more important than storage cost, while the range of the order lead time has a higher impact than the one of the product lead time.

Figure 8 exhibits the main effects plot. It graphically shows the influence of the various controllable and noise factors on supply chain net profit. It should be remarked that, according to the main goal of the paper, it represents the screening. Hence some of the effects that can be seen are negligible. Note that neither the production nor the transportation capacities have proven to be significant. Surprisingly, the $\mathrm{Z}$ safety parameter does not have a considerable impact on the net profit, while this metric does not have a significant relationship with the standard deviation of the demand. In addition, it is not possible to verify, at the confidence level $95 \%$, a great negative effect caused by the defective product rate on the net profit. 
Table 3. DoE screening: Effect analysis for the whole supply chain net profit.

\begin{tabular}{|c|c|c|c|c|}
\hline Factor & Estimate & Std Error & t-ratio & p-value \\
\hline Intercept & $4,864.30$ & $3,535.65$ & 1.38 & 0.1940 \\
\hline Management policy (X1) ${ }^{*}$ & $-5,190.72$ & 574.69 & -9.03 & 0.0000 \\
\hline Production capacity (X2) & -0.09 & 0.13 & -0.70 & 0.4991 \\
\hline Transport capacity (X3) & -0.18 & 0.13 & -1.35 & 0.2019 \\
\hline$Z$ safety parameter (X4) & $-1,911.71$ & $1,273.53$ & -1.50 & 0.1592 \\
\hline St. Dev of the demand (Z5) & -50.23 & 67.86 & -0.74 & 0.4734 \\
\hline Transport cost $(\mathrm{Z} 6)$ & $-624,120.30$ & $166,365.90$ & -3.75 & 0.0028 \\
\hline Storage cost $(Z \bar{Z})$ & $-462,745.70$ & $171,117.30$ & -2.70 & 0.0192 \\
\hline Defective products rate (Z8) & -0.50 & 0.24 & -2.08 & 0.0596 \\
\hline Gross margin of the levels (Z9) & $77,435.22$ & $3,413.62$ & 22.68 & 0.0000 \\
\hline Order lead time: Range (Z10) & $4,743.19$ & $1,241.29$ & 3.82 & 0.0024 \\
\hline Product lead time: Range (Z11) & $-1,035.85$ & 442.83 & -2.34 & 0.0374 \\
\hline
\end{tabular}

Note $\quad\left(^{*}\right)$ : In this categorical variable, the results refer to OUT in comparison with DBR.

(1): This table highlights the significant factors at the confidence level $95 \%$.

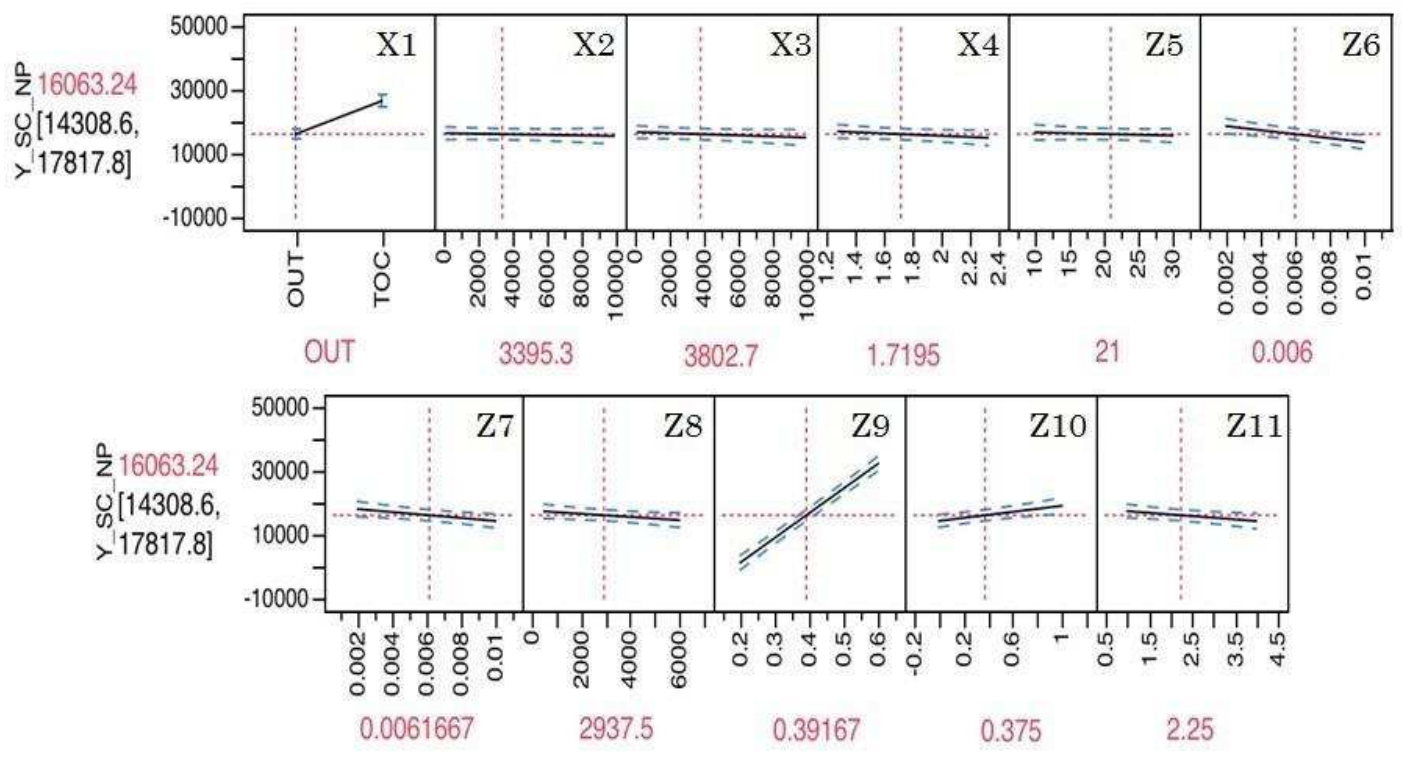

Fig. 8. DoE screening: Main effects of the different factors on supply chain performance.

\subsection{Understanding the Improvement.}

The previous results demonstrate the improvement induced by the holistic management on the supply chain in economic terms, but how is this achieved? To answer this question, we focus on block 2 of the DoE: the central points. Table 4 shows the average and the standard deviation of the operational indicators in these tests when the system is managed through the OUT replenishment policy (runs 19, 21, and 23) and the DBR methodology (runs 20, 22, 24). 
Table 4. Operational indicators in block 2: mean and standard deviation (in brackets).

\begin{tabular}{cccc}
\hline Management & Throughput & Operating Expense & Inventory \\
\hline OUT & $\$ 24,249.30(\$ 328.35)$ & $\$ 5,319.94(\$ 312.79)$ & $\$ 2,830.00(\$ 428.00)$ \\
\hdashline$D B R$ & $\$ 35,193.20(\$ 187.48)$ & $\$ 4,579.09(\$ 71.29)$ & $\$ 2,882.53(\$ 50.97)$ \\
\hline
\end{tabular}

These results outline that the net profit grows due to two reasons: the throughput tends to increase, and the operating expense tends to decrease. Nonetheless, the contribution of the throughput has a greater significance. It is not a surprise: the TOC proposes an innovative management focused on increasing the throughput, whereas traditional practices are aimed at cutting costs. However, and paradoxically, the DBR method also leads to a cost reduction. Table 5 helps to interpret these results, displaying some key indicators that underline the differences between both approaches.

Table 5. Total sales, average time in the system (per unit), rolled throughput yield (RTY, or percentage of defect free units), and Bullwhip Effect (ratio between the variance of the overall inventory and the variance of the demand): mean and standard deviation (in brackets).

\begin{tabular}{crrrr}
\hline Management & Total sales & $\begin{array}{c}\text { Average time } \\
\text { in the system }\end{array}$ & RTY & $\begin{array}{r}\text { Bullwhip } \\
\text { Effect }\end{array}$ \\
\hline OUT & $22,027.0(536.6)$ & $58.07(10.12)$ & $89.84 \%(0.82 \%)$ & $392.21(48.35)$ \\
\hdashline$D B R$ & $27,552.7(90.0)$ & $34.16(0.89)$ & $93.37 \%(0.23 \%)$ & $127.48(49.36)$ \\
\hline
\end{tabular}

The increase in the throughput comes mainly from the rise in the total sales in the system, i.e. the reduction in lost sales achieved by the DBR method. Note that the increase by $25 \%$ in total sales translates into a higher increase $(45 \%)$ in the throughput due to the operating leverage. The large amount of lost sales, even when working with high service levels, within the reductionist system is a direct consequence of the problems caused by the Bullwhip Effect (variability along the supply chain is significantly higher). Notice lost sales increase dramatically even though the inventory level is similar (see the inventory in Table 4, or the average time in the system in Table 5), since it is not appropriately distributed in the supply chain to protect the bottleneck.

A growth in sales usually leads to an increase in operating expense. However, it does not occur in this case. The reason is the total time of the product in the supply chain. 
With the OUT policy, the product tends to be unnecessarily (far from the customer) stored, and consequently the percentage of defective products increases (i.e. the rolled throughput yield reduces). As a result of both effects, storage costs are dramatically higher in the reductionist approach.

It can also be noticed from inspection of Tables 4 and 5 that variations in results are smaller with the DBR method. That is, the reductionist approach is more sensitive to the repetitiveness of the experiment. The holistic approach seems to be more robust.

\subsection{Analysis by Nodes of the Results.}

Once TOC economic superiority in this noise-extended environment has been verified when compared to the classic OUT policy for the overall supply chain, this leads to an unavoidable key question: Do all supply chain members benefit in the same way from collaboration? Therefore, the research is moved towards the node-by-node analysis. We have carried out the same study for the net profit of each member.

When results are observed in detail, it can be noticed that the wealth generated by the holistic approach is not equitably distributed along the various supply chain echelons. Table 6 exhibits the average net profit of the four nodes both when the DBR methodology and the OUT policy manage the supply chain. Figure 9 displays the main effects of the management policy factor in order to graphically show the significant difference in how members benefit from collaboration.

Table 6. Local results of the same treatment when both alternatives are used to manage the supply chain.

\begin{tabular}{|c|c|c|c|}
\hline Factor & OUT_Net profit & DBR_Net profit & Percentage increase \\
\hline Supply Chain & $\$ 16,165.24$ & $\$ 26,342.20$ & $+62.96 \%$ \\
\hline Factory & $\$ 2,175.99$ & $\$ 8,777.05$ & $+303.36 \%$ \\
\hline Distributor & $\$ 2,589.05$ & $\$ 5,477.56$ & $+111.57 \%$ \\
\hline Wholesaler & $\$ 5,486.78$ & $\$ 6,466.04$ & $+17.85 \%$ \\
\hline Retailer & $\$ 5,913.42$ & $\$ 5,621.55$ & $-4.94 \%$ \\
\hline
\end{tabular}




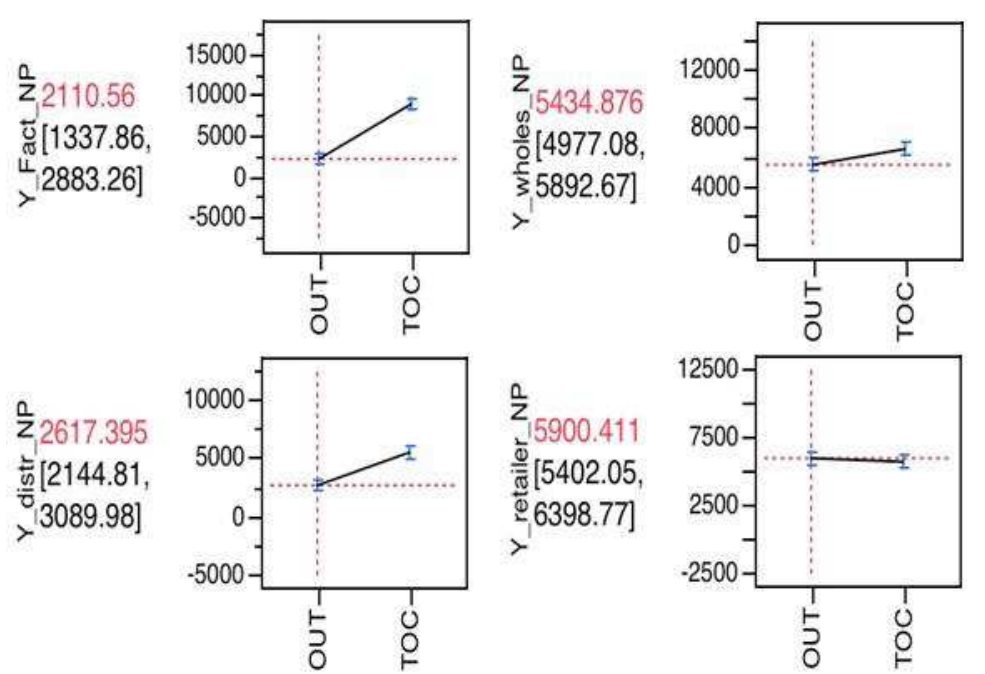

Fig. 9. DoE screening: Main effects of the management policy factor on the various nodes.

When analyzing the reductionist approach, the dramatic economic consequences of the Bullwhip Effect within the supply chain arise. This phenomenon creates large differences in profits along the distribution system, although the gross margin is the same and the throughput only undergoes slight changes (due to defective products and storage). These variations lead to an increase in operating expense as it moves away from the customer. Nonetheless, there is not a great difference in factory and distributor. The reason could be the production limitation. This constraint is a good solution to tame the Bullwhip Effect at the factory [36], as prevents the factory from generating large variations, smoothing its behavior. This limitation tends to increase lost sales at the retailer, but in certain scenarios the cost reduction compensates it.

As seen, the great increase in overall profits induced by the holistic management comes both from the growth in throughput (Goldratt's practices are aimed at protecting the bottleneck) and the decrease in operating expense (as the Bullwhip Effect is significantly reduced). Nevertheless, as TOC solution is based on keeping the inventory near to customer in order to minimize lost sales, the retailer will assume higher inventory costs. Thus, as shown in Table 6, cost distribution varies considerably. This causes that, when the DBR method is used, those members distant to customer 
obtain better results (in case of equality in margins), especially if unit costs are high. In the factory, storage costs are more relevant since the lead time is greater, while in the rest of the nodes, transport costs are more relevant.

In summary, although there is a dramatic improvement generated by the collaborative approach in the supply chain (overall profit is increased by 63\%), this increase is much higher as the members move away from the customer. In fact, global optimization might lead to economic losses in some nodes -this could happen in the retailer in the case analyzed. In this context, the interest in adopting a collaborative policy will be very different at the various nodes. Therefore, if collaboration does not generate fair benefits in all echelons, some barriers to holism emerge in the supply chain, and the system would run into a non-optimal solution.

This node-by-node study brings evidence of the need for the fifth feature according to the Simatupang and Sridharan's framework [10]. Some kind of incentive alignment is required in order to achieve the system optimal solution through a Nash equilibrium, i.e. without incentives to deviate. That is, sharing costs, risks, and benefits among the various members is essential for taking the system from reductionism to holism. Thus, experimentation through simulation allows manager to anticipate to this problem by defining an appropriate cost structure within the supply chain.

\section{Main Conclusions and Future Research}

Although holistic supply chain solutions are considered to outperform traditional reductionist alternatives, they are not yet widespread since the adoption of an efficient collaborative solution requires a complex decision-making process to implement an appropriate framework [37]. This research focuses on this transition from local to 
global optimization understanding experimentation as a powerful engine for gaining knowledge. We employ an agent-based approach as a model-driven decision support system, where practitioners can explore a complex network of interdependences that would be unmanageable through other methodologies.

There are some aspects that the authors (with practical experience in supply chains and change management) consider essential in this transition. One of them is the educational phase that is required to move supply chain participants away from their natural individualistic behavior. Simulation can lead them to gain confidence in collaborative practices [38], since motivation is crucial in this decision-making process. These studies can reproduce the known environment (which would be inconceivable through an analytical approach), and allow managers to explore complex cause-effect relationships within an inexpensive and risk-free context.

This work provides evidence of TOC economic robustness in comparison with the OUT inventory policy when managing a four-echelon supply chain with several noise sources. The overall improvement came mainly from the increase of the throughput, which is a strong argument against traditional cutting costs-based management. However, paradoxically, the operating expense is also reduced due to the taming in the Bullwhip Effect and hence the reduction in storage costs. Several experiments have been carried out to statistically confirm this hypothesis, and the average increase in the net profit of the whole supply chain has been $63 \%$.

Once the improvement is perceived, supply chain actors focus on the implementation. In the required integrative framework, information sharing acts as an (indispensable) enabler. This creates a visibility environment, which facilitates decision making to be carried out by a headquarter office that accounts for the interest of the whole system. 
To find an appropriate collaborative solution for the supply chain, it is essential to integrate processes, synchronize decisions, and define a systemic performance scorecard [10]. To solve these issues, a solution based on Goldratt's TOC is proposed, in which the DBR method defines the collaborative behavior and the TA is used to determine the impact of the decisions on supply chain performance.

We provide evidence of the fact that the net profit distribution significantly varies when adopting collaborative solutions. While the OUT tends to damage upstream echelons due to the Bullwhip Effect, the TOC approach usually favors these members. Under these circumstances, aligning incentives within the supply chain is required. In this sense, trust is essential, and risks and benefits must be shared in order to avoid opportunistic behaviors [39]. Computer-based prototypes can be used by managers as business laboratories to define an appropriate cost structure within the supply chain.

Once studied the widely used Beer Game (serial) supply chain, future work is aimed at confirming the robustness of the holistic approach in divergent networks topologies.

In addition, we intend to further explore the reductionism-to-holism transition in terms of incentive alignment. One simple way companies can define a robust adaptive mechanism (it must be able to function over time) is by altering contracts with the aim of fairly distributing the benefit induced by collaboration. It means establishing linear contracts so that each node is rewarded according to its contribution.

A third avenue for future work is to incorporate Lean Management mechanisms in the agent-based system. We aim to use simulation for contrasting the TOC with the most known holistic paradigm. Our preliminary research suggests that while there is not a significant difference between both methodologies in low-noise scenarios, the TOC makes a difference when the supply chain faces harmful noise conditions. 


\section{Acknowledgements}

The authors deeply appreciate the Government of the Principality of Asturias (Severo Ochoa program, ref. BP13011) and the Banco Sabadell Foundation for financially supporting this research. Borja Ponte would like to thank Prof. Stephen Disney for his outstanding advice on this topic during his research stay at the Cardiff Business School.

\section{References}

[1] T.M. Simatupang, A.C. Wright, R. Sridharan, Applying the Theory of Constraints to supply chain collaboration, Supply Chain Manag.: An Int. J., 9 (1) (2004), 57-70.

[2] J. Costas, B. Ponte, D. De la Fuente, R Pino, R., J. Puche, J. Applying Goldratt's Theory of Constraints to reduce the Bullwhip Effect in a supply chain through agentbased modeling, Expert Syst. with Appl. 42 (4) (2015) 2049-2060.

[3] G.P. Cachon, P.H. Zipkin, Competitive and cooperative inventory policies in a twostage supply chain, Manag. Sci., 45 (7) (1999) 936-953.

[4] T.M. Simatupang, R. Sridharan, The collaborative supply chain, Int. J. of Logist. Manag. 13 (1) (2002) 15-30.

[5] J. Dejonckheere, S.M. Disney, M.R. Lambrecht, D.R. Towill, Measuring and avoiding the Bullwhip Effect: A control theoretic approach, Eur. J. of Oper. Res. 147 (3) (2003) 567-590.

[6] N. Gilbert, Agent-based models, Sage Publications, London, 2008.

[7] D.J. Power, R. Sharda, Model-driven decision support systems: Concepts and research directions, Decis. Support Syst. 43 (3) (2007) 1044-1061.

[8] E.M. Goldratt, Theory of Constraints, North River Press, Croton-on-Hudson, 1990. 
[9] F. Chen, Z. Drezner, J.K. Ryan, D. Simchi-Levi, Quantifying the Bullwhip Effect in a simple supply chain: The impact of forecasting, lead times, and information, Manag. Sci. 46 (3) (2000) 436-443.

[10] T.M. Simatupang, R. Sridharan, An integrative framework for supply chain collaboration, Int. J. of Logist. Manag. 16 (2) (2005) 257-274.

[11] D.W. Smith, The measurement nightmare, Lucie Press, Boca Raton, 2000.

[12] H.L. Lee, V. Padmanabhan, S. Whang, The Bullwhip Effect in supply chains, Sloan Manag. Rev. 38 (3) (1997) 93-102.

[13] M. Holweg, S. Disney, J. Holmström, J. Småros. Supply Chain Collaboration: Making Sense of the Strategy Continuum. Eur. Manag. J. 23 (2) (2005) 170-181.

[14] M. Moschandreas, The role of opportunism in transaction cost economics, J. of Econ. Issues 31 (1) (1997) 39-57.

[15] E.M. Goldratt, E. Schragenheim, C.A. Ptak, Necessary but not sufficient, North River Press, Croton-on-Hudson, 2000.

[16] V.J. Mabin, S.J. Balderstone, The performance of the theory of constraints methodology: analysis and discussion of successful TOC applications, Int. J. of Oper. \& Prod. Manag. 23 (6) (2003) 568-595.

[17] T. Corbett, Throughput accounting: TOC's management accounting system, North River Press, Croton-on-Hudson, 1998.

[18] S. Cannella, J. Ashayeri, P.A. Miranda, M. Bruccoleri, Current economic downturn and supply chain: the significance of demand and inventory smoothing, Int. J. of Comput. Integr. Manuf. 27 (3) (2014) 201-212. 
[19] J.D. Sterman, Modeling managerial behavior: Misperceptions of feedback in a dynamic decision making experiment, Manage. Sci. 35 (3) (1989) 321-339.

[20] S. Karlin, Dynamic inventory policy with varying stochastic demands, Manage. Sci. 6 (3) (1960) 231-258.

[21] K.L. Croxon, S.J. García-Dastugue, D.M. Lambert, D.S. Rogers, The supply chain management processes, Int. J. of Logist. Manag. 12 (2) (2001) 13-36.

[22] K. Youngman, A Guide to Implementing the Theory of Constraints, 2009, available at http://www.dbrmfg.co.nz/ (accessed 26 March 2015).

[23] H.H. Wu, C.P. Chen, C.H. Tsai, T.P. Tsai, A study of an enhanced simulation model for TOC supply chain replenishment system under capacity constraint, Expert Syst. with Appl. 37 (9) (2010), 6435-6440.

[24] H.H. Wu, A.H.I. Lee, T.P. Tsai, A two-level replenishment frequency model for TOC supply chain replenishment systems under capacity constraint, Comput. \& Ind. Eng. 72 (1) (2014) 152-159.

[25] F. Castiglione, Diffusion and aggregation in an agent based model of stock market fluctuations, Int. J. of Mod. Phys. C 11 (5) (2000) 865-879.

[26] D.C. Chatfield, T.P. Harrison, J.C Hayya, SISCO: An object-oriented supply chain simulation system, Decis. Support Syst. 42 (1) (2006) 422-434.

[27] C.M. Macal, M.J. North, Tutorial on agent-based modeling and simulation, in WSC'05 Proceedings of the 37th Conference on Winter Simulation, Orlando (2005) 2-15.

[28] U. Wilensky, NetLogo, 1999, available at http://ccl.northwestern.edu/netlogo/ (accessed 28 April 2015).

[29] A. Getchell, Agent-based modeling, Phys. 22 (6) (2008) 757-767. 
[30] E. Bonabeau, Agent-based modeling: Methods and techniques for simulating human systems, Proceedings of the National Academy of Sciences of the United States of America 99 (3) (2002) 7280-7287.

[31] W. Zinn, H. Marmorstein, Comparing two alternative methods of determining safety stock levels: The demand and the forecast systems, J. of Bus. Logist. 11 (1) (1990) 95-110.

[32] S.M. Disney, A. Maltz, X. Wang, R.D. Warburton, Inventory management for stochastic lead times with order crossovers, Eur. J. of Oper. Res. 248(2) (2016) 473-486.

[33] J. Ravichandran, Six-sigma milestone: an overall sigma level of an organization, Total Qual. Manage. 17(8) (2006) 973-980.

[34] R.A. Fisher, Statistical Methods, Experimental Design and Scientific Inference, Oxford University Press, New York, 1990.

[35] J. Sall, A. Lehman, A., M.L. Stephens, L. Creighton, L. JMP start statistics: a guide to statistics and data analysis using JMP, SAS Institute, Cary, 2012.

[36] S. Cannella, E. Ciancimino, A.C. Márquez, Capacity constrained supply chains: A simulation study. Inter. J. of Simul. and Process Model. 4 (2) (2008) 139-147.

[37] J. Puche, B. Ponte, J. Costas, R. Pino, D. de la Fuente, Systemic approach to supply chain management through the viable system model and the theory of constraints, Prod. Plan. \& Control in press.

[38] M. Holweg, J. Bicheno, Supply chain simulation - a tool for education, enhancement and endeavour, Int. J. of Prod. Econ. 78 (2) (2002) 163-175.

[39] X. Fu, M. Dong, S. Liu, G. Han, Trust based decisions in supply chains with an agent, Decis. Support Syst. 82 (1) (2016) 35-46. 